\title{
Aplicação de metodologia de análise hierárquica (AHP) para priorização de intervenção em estações de tratamento de esgotos - Estudo de caso na Bacia do Siqueira, Fortaleza/CE
}

\section{Application of analytic hierarchy process(AHP) for prioritization of intervention in wastewater treatment plants - Case study in the Siqueira Basin, Fortaleza/CE}

\section{Data de entrada: 28/03/2018 \\ Data de aprovação: 04/02/2019} Grazielly dos Santos Lima ${ }^{1 *}$ | Ana Bárbara de Araújo Nunes ${ }^{1}$ | Antônio Marcelo Costa Magalhães ${ }^{1}$ | DOI: https://doi.org/10.36659/dae.2020.051
Vanessa Ribeiro Campos ${ }^{1}$

ORCID ID

Lima GS (iD) https://orcid.org/000-0001-6857-384X

Nunes ABA (i) https://orcid.org/0000-0001-5845-6252
Magalhães AMC iD https://orcid.org/0000-0002-2359-2198

Campos VR (iD) https://orcid.org/0000-0002-3981-3362

\section{Resumo}

A realidade das condições sanitárias no Ceará ainda é precária, principalmente no que se refere ao esgotamento sanitário, acarretando impactos diretos ao meio ambiente e para a sociedade do entorno. Um dos principais desafios é o gerenciamento das unidades de tratamento de esgotos já existentes. Diante disso, o objetivo deste estudo de caso é propor uma metodologia multicriterial de apoio à decisão que priorize intervenções às Estações de Tratamento de Esgotos (ETEs) da Bacia do Siqueira, localizada em Fortaleza - CE. O método escolhido é o Analytic Hierarchy Process (AHP), que trabalha com a problemática de hierarquização e permite correlacionar uma grande quantidade de alternativas e critérios. Apesar da sensibilidade do método às variações de julgamentos de valor realizadas pelos decisores, o caráter prático da pesquisa é alcançado, haja vista que a metodologia proposta está embasada em critérios de facilitada reprodutibilidade, o que permitirá ações por parte dos órgãos licenciadores e fiscalizadores das atividades de uma ETE ou por parte da própria companhia local de saneamento a fim de eliminar ou atenuar possíveis não conformidades identificadas.

Palavras-chave: Análise Multicritério. AHP. Estação de Tratamento de Esgotos.

\section{Abstract}

The reality of Ceará's sanitary conditions is still precarious, mainly on sanitary sewage, causing direct impacts on the environment and its surrounding communities. One of the main challenges is the management of the already existing sewage treatment units. Before that, the purpose of this case study is to propose a multicriterial methodology that supports decision which prioritizes interventions to the Wastewater Treatment Plants (WTP) of the Siqueira basin, located in Fortaleza-CE. The chosen method is the Analytic Hierarchy Process (AHP), which works with the hierarchical problem and

\footnotetext{
${ }^{1}$ Universidade Federal do Ceará (UFC) - Fortaleza - Ceará -Brasil.

* Autora correspondente: graziellyslimaagmail.com.
} 
allows to correlate many alternatives and criteria. Despite the sensitivity of the method to variations of value judgment made by the decision makers, the practicality of the research is achieved, given that the proposed methodology is based on criteria of facilitated reproducibility, which will allow actions by the licensing agencies and inspectors of the activities of an WTP or by the local sanitation company itself in order to eliminate or mitigate possible identified nonconformities.

Keywords: Multi-criteria Analysis. AHP. Wastewater Treatment Plants.

\section{INTRODUÇÃO}

Segundo a Constituição Federal, em seu artigo 225 , todos têm direito ao meio ambiente ecologicamente equilibrado, bem de uso comum do povo e essencial à sadia qualidade de vida. Uma forma de assegurar esse direito é a implantação e a operação de forma adequada dos sistemas de saneamento básico. A Lei nº. 11.445/2007 define saneamento como o conjunto dos serviços, infraestruturas e instalações operacionais de abastecimento de água, esgotamento sanitário, limpeza e drenagem urbana, manejo de resíduos sólidos e de águas pluviais.

Quanto à efetividade desses serviços, o mais recente diagnóstico do Sistema Nacional de Informações sobre Saneamento (SNIS), realizado em 2016, mostrou que os índices brasileiros de cobertura atingiram uma média total de $83,3 \%$ para abastecimento de água e de $51,9 \%$ para coleta de esgotos, onde apenas $74,9 \%$ dos esgotos coletados recebem tratamento. Embora estes índices venham aumentando em relação aos últimos anos, ainda é bastante comum encontrarmos uma realidade precária das condições sanitárias, decorrentes tanto da carência crônica de recursos para investimento como da deficiência ou da ausência de políticas públicas, principalmente no que se refere ao esgotamento sanitário (BERNARDES; SCÁRDUA; CAMPANA, 2006).

No estado do Ceará, a Companhia de Água e Esgoto (CAGECE), presente atualmente em $151 \mathrm{mu}$ nicípios, apresenta um índice geral de cobertura do sistema de esgotamento sanitário de apenas
41,7\%. Já Fortaleza, capital do estado, conta com um índice um pouco maior, mas ainda baixo, de 62,0\% (CAGECE, 2018). Segundo Magalhães (2017), somada a essa deficiência, há uma matha de desafios de gerenciamento das unidades de tratamento de esgoto já existentes, devido a diversos fatores, tais como sobrecarga de vazão, problemas de ordem operacional, ligações clandestinas, furtos, roubos e deterioração de equipamentos e periféricos. Assim, muitas unidades estão continuamente apresentando resultados de inconformidade, não obedecendo ao exigido pela legislação, contribuindo assim para a contaminação do meio ambiente e para a proliferação de doenças, o que interfere na produtividade do indivíduo e na qualidade de vida da população, sendo, portanto um problema de ordem ambiental, social e econômica.

Diante dessa situação, o objetivo deste trabalho é propor um ordenamento de priorização de intervenção às Estações de Tratamento de Esgotos (ETEs) da Bacia do Siqueira, localizada na cidade de Fortaleza - CE. Para isto, buscou-se utilizar uma metodologia de Apoio à Decisão que integre a subjetividade do processo a uma conjuntura complexa que envolve critérios ambientais, operacionais e sociais.

Nesse contexto, o método escolhido para a realização desse trabalho foi o Analytic Hierarchy Process (AHP), que trabalha com a problemática de hierarquização e permite correlacionar uma grande quantidade de alternativas e critérios, permitindo uma fácil compreensão e meIhor avaliação do problema, buscando atender 
aos valores e interesses daqueles efetivamente envolvidos no processo decisório, permitindo ações por parte dos órgãos licenciadores e fiscalizadores das atividades de uma ETE no sentido de priorizar sua ação fiscalizatória ou por parte da própria companhia local de saneamento que procure eliminar ou atenuar possíveis não conformidades identificadas.

\section{METODOLOGIA}

A pesquisa compreende as Estações de Tratamento de Esgotos da bacia do Siqueira, também identificada pela prefeitura como bacia do Maranguapinho. Localizada na porção oeste de Fortaleza, é a segunda maior bacia do município, ocupando uma área de $84,73 \mathrm{~km}^{2}$. A Fig. 1 apresenta o mapa da bacia com as respectivas ETEs do presente estudo de caso.

Figura 1 - Mapa com as ETEs abordadas no estudo de caso

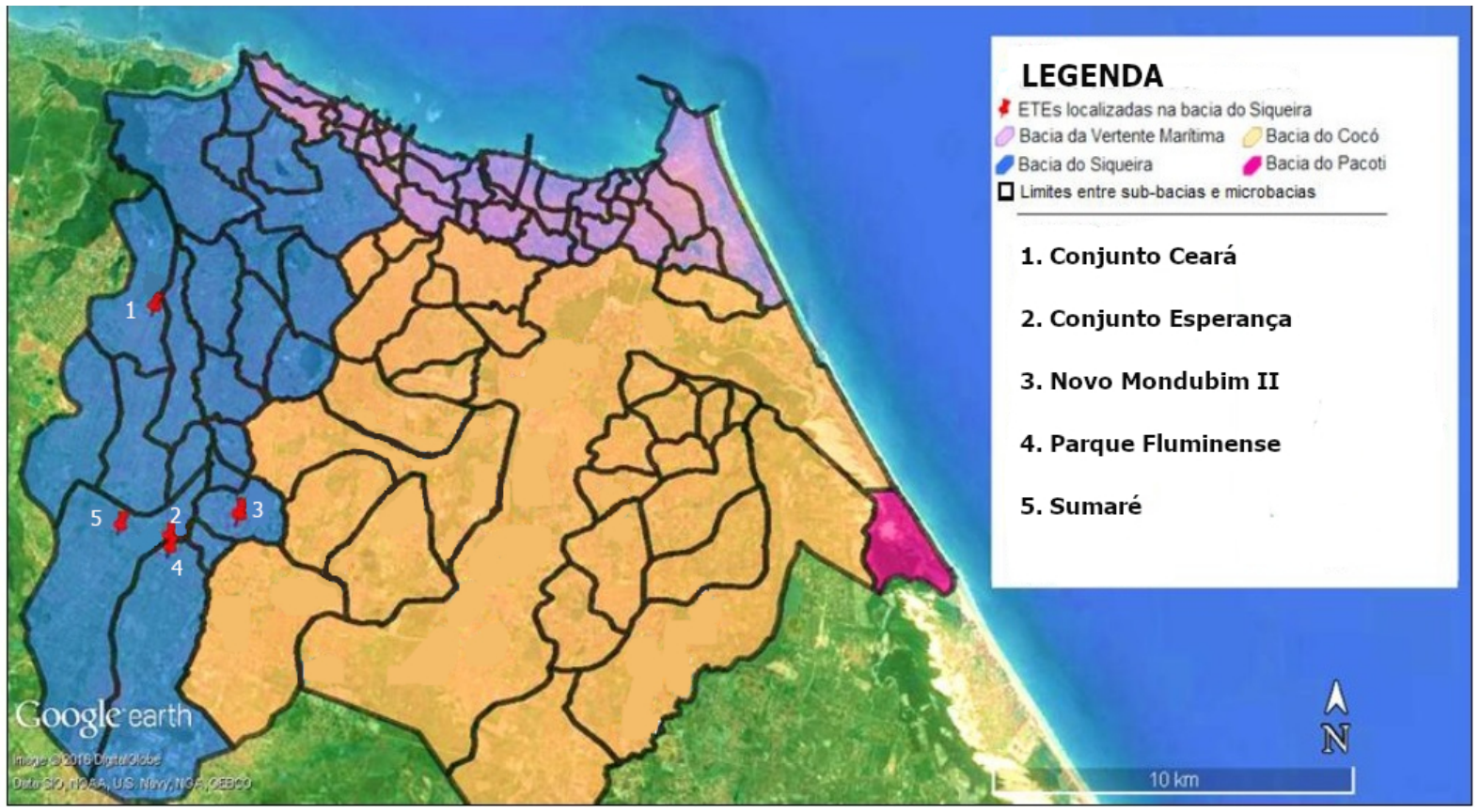

Fonte: Magalhães (2017).

Segundo Carleial e Araújo (2010), o percurso feito pelo rio principal abrange áreas de grandes concentrações industriais e populacionais, resultando em impactos ambientais de grandes proporções, incidindo diretamente na qualidade de vida das comunidades que residem em seu entorno, o que justifica a escolha da área para o estudo de caso.

Uma vez amadurecida a problemática inicial, definidos os objetivos e consolidada parceria com a CAGECE, compreendeu-se que a metodologia a ser proposta deveria incorporar critérios de diferentes naturezas, bem como a percepção da relevância destes critérios por profissionais que tenham no exercício da sua profissão ligação direta com a temática abordada. Assim, efetuouse a busca por um modelo multicritério de apoio à decisão que fosse capaz de atender aos requisitos desta pesquisa. A seguir, apresenta-se uma descrição da metodologia proposta. 


\subsection{Identificação dos Atores de Decisão}

De acordo com Roy (1996), denomina-se ator (stakeholder, em inglês) todo indivíduo ou grupo de indivíduos de um processo decisório que possui influência direta ou indireta na decisão através de seu sistema de valores.

Magalhães (2017) afirma que os atores envolvidos no processo decisório precisam ter contato direto com a realidade do tema pesquisado e qualificação técnica para responder com acurácia os questionamentos propostos, além de disponibilidade para colaborar com a pesquisa.

Assim, para o processo decisório foi feita a seleção de nove atores de decisão, oriundos de três diferentes grupos. A Tabela 1 objetiva descrever de forma sucinta o perfil técnico/profissional dos decisores, alocando-os segundo a sua respectiva classe.

Tabela 1 - Perfil técnico/profissional dos decisores

\begin{tabular}{|c|c|}
\hline Classe de decisor & Perfil técnico/profissional \\
\hline \multirow{3}{*}{ Gestores da CAGECE } & Engenheiro Civil especialista em Saneamento Básico. Trabalha há 2 anos diretamente na gestão das ETEs. \\
\hline & Engenheiro Sanitarista e Ambiental. Trabalha há 2 anos diretamente na gestão das ETEs. \\
\hline & $\begin{array}{l}\text { Topógrafo com especialização em saneamento ambiental. Trabalha como supervisor das ETEs há } 7 \text { anos, já exercendo } \\
\text { outras funções correlatas. }\end{array}$ \\
\hline \multirow{3}{*}{ Autoridades de órgãos ambientais } & $\begin{array}{l}\text { Engenheiro Químico com especialização em saneamento ambiental. Trabalha há } 10 \text { anos na SEUMA exercendo } \\
\text { funções de gerenciamento na Célula de Controle de Efluente. }\end{array}$ \\
\hline & $\begin{array}{l}\text { Engenheiro Químico com especialização em saneamento ambiental. Longa experiência à frente de cargo } \\
\text { gerencial na ACFOR. }\end{array}$ \\
\hline & $\begin{array}{l}\text { Engenheiro Químico. Trabalha há } 5 \text { anos na SEUMA exercendo funções de licenciamento, fiscalizações e controle na } \\
\text { Célula de Controle de Efluente. }\end{array}$ \\
\hline \multirow{3}{*}{$\begin{array}{l}\text { Acadêmicos especialistas no } \\
\text { tratamento de esgotos }\end{array}$} & $\begin{array}{l}\text { Engenheiro Sanitarista e de Segurança do Trabalho, doutor em Recursos Hídricos, MBA em Gestão Empresarial, } \\
\text { professor adjunto do Departamento de Engenharia Hidráulica e Ambiental da Universidade Federal do Ceará. }\end{array}$ \\
\hline & $\begin{array}{l}\text { Engenheiro Civil, PhD em Saneamento Ambiental, professor adjunto do Departamento de Engenharia Hidráulica e } \\
\text { Ambiental da Universidade Federal do Ceará e consultor de empresas públicas e privas na área de tratamento } \\
\text { de esgoto. }\end{array}$ \\
\hline & $\begin{array}{l}\text { Engenheiro Civil, doutor em Saneamento Ambiental, professor adjunto do Departamento de Engenharia Hidráulica e } \\
\text { Ambiental da Universidade Federal do Ceará. }\end{array}$ \\
\hline
\end{tabular}

Fonte: Elaborada pela autora (2018)

\subsection{Definição dos Critérios de Avaliação}

Para que um agente de decisão possa efetuar uma escolha sobre um conjunto de alternativas ou ações potenciais, supõe-se que sua análise será baseada em diferentes eixos de avaliação, denominados eixos de significância. $\mathrm{Na}$ escolha entre diversas alternativas, características devem ser consideradas. Essas características são denominadas atributos. Quando a esses atributos acrescenta-se um mínimo de informação relativa às preferências dos decisores, elas convertem-se em critérios (GOMES E GOMES, 2014).

Para o processo de definição de critérios foi selecionado um representante de cada uma das classes de decisores. Nesta etapa, os decisores exprimiam suas percepções tendo por base não somente os dados já reportados pela literatura ou pelos documentos oficiais da prefeitura, mas tendo completo acesso às informações coletadas em campo, perfil das informações disponíveis nos bancos de dados da CAGECE ou que poderiam ser cedidas pelos órgãos ambientais responsáveis pela fiscalização destes empreendimentos. Deste modo, o processo de concepção dos critérios foi desenvolvido não somente segundo as características das ETEs em questão, mas também sempre considerando a viabilidade do mecanismo de obtenção das informações pertinentes. 
Conforme orientam Brans e Mareschal (1994), metodologias em que os critérios são simplesmente agregados, sem estabelecimento prévio da importância relativa entre eles, comumente podem apresentar falhas; deste modo, uma vez que os critérios são estabelecidos e de acordo com as diretrizes próprias da metodologia adotada, fazse necessário o estabelecimento de uma ponderação sob os mesmos, que reflita o sistema de va- lores dos decisores. Diante disso, aplicou-se um questionário a todos os nove decisores, a fim de perceber a relevância de cada um dos critérios.

Vista a amplitude do estudo, os critérios foram divididos em três classes: ambiental, operacional e social. A Tabela 2 exibe quais critérios foram selecionados após o processo de análises e entrevistas com os atores de decisão.

Tabela 2 - Critérios avaliados pelos atores de decisão

\begin{tabular}{|c|c|c|}
\hline Classe & & Critério \\
\hline \multirow{4}{*}{ Ambiental } & (C1) & $\mathrm{pH}$ \\
\hline & (C2) & Demanda Química de Oxigênio \\
\hline & (C3) & Sólidos Suspensos Totais \\
\hline & (C4) & Escherichia coli \\
\hline \multirow{7}{*}{ Operacional } & (C5) & Mau desempenho da unidade de desarenação \\
\hline & (C6) & Maus odores \\
\hline & (C7) & Descarte inadequado de lodo \\
\hline & (C8) & Assoreamento ou presença de resíduos sólidos \\
\hline & (C9) & Problemas no estado de conservação das unidades \\
\hline & (C10) & Problemas no estado de conservação predial \\
\hline & (C11) & Problemas de segurança \\
\hline \multirow{3}{*}{ Social } & (C12) & Índice de Desenvolvimento Humano dos Bairros \\
\hline & $(\mathrm{C} 13)$ & Percentual de domicílios ligados à rede de água do bairro em que a ETE está inserida \\
\hline & (C14) & Percentual de domicílios ligados à rede de esgoto do bairro em que a ETE está inserida \\
\hline
\end{tabular}

Fonte: Elaborada pela autora (2018)

\subsubsection{Critérios Ambientais}

A Portaria no 154/2002 da SEMACE é a legislação em instância estadual que dispõe os padrões de qualidade para efluentes líquidos tanto para as indústrias ou qualquer fonte poluidora localizadas em áreas não dotadas de rede pública de esgoto provida de sistema de tratamento, como também para das instituições prestadoras de serviços públicos de esgotamento sanitário. Deste modo, foi a partir dos parâmetros exigidos por esta legislação que se buscou constituir o estudo de quais parâmetros ambientais iriam compor este trabalho.

Deste modo, a dinâmica do processo decisório resultou na escolha de quatro parâmetros exigidos pela Portaria n 154/2002 da SEMACE. Foram eles:
- Potencial hidrogeniônico - pH;

- Demanda Química de Oxigênio - DQQO [mg/L];

- Sólidos em Suspensão Totais - SST [mg/L];

- Coliformes Fecais - E. coli [NMP/100 mL].

\subsubsection{Critérios Operacionais}

Os critérios operacionais propostos visam identificar a observância de possíveis não conformidades nas ETEs que compõem o estudo de caso. O Diagnóstico das atuais condições de drenagem do município de Fortaleza (FORTALEZA, 2013a) documento que integra o Plano Municipal de Saneamento Básico de Fortaleza - apresenta uma série de problemas identificados nas ETEs. 
Entretanto, para a construção da base de informações a ser utilizada nesta pesquisa, cada uma das não conformidades propostas foi reavaliada junto com os supervisores das ETEs, a partir das observações em campo possibilitadas pelas visitas realizadas, de modo a fazer uma atualização dos problemas já retratados pelo referido documento, seja pela inclusão de novas situações adversas, seja pela retirada daquelas que já tiveram sua problemática sanada. Os critérios operacionais avaliados para cada estação foram:

- Mau desempenho na unidade de desarenação;
- Maus odores;

- Descarte inadequado de lodo;

- Assoreamento ou presença de resíduos sólidos;

- Problemas no estado de conservação das unidades de tratamento;

- Problemas no estado de conservação predial;

- Problemas de segurança.

A Fig. 2 mostra algumas das não conformidades observadas durante as visitas da etapa preliminar:

Figura 2 - Parte dos problemas verificados durante visitas de campo

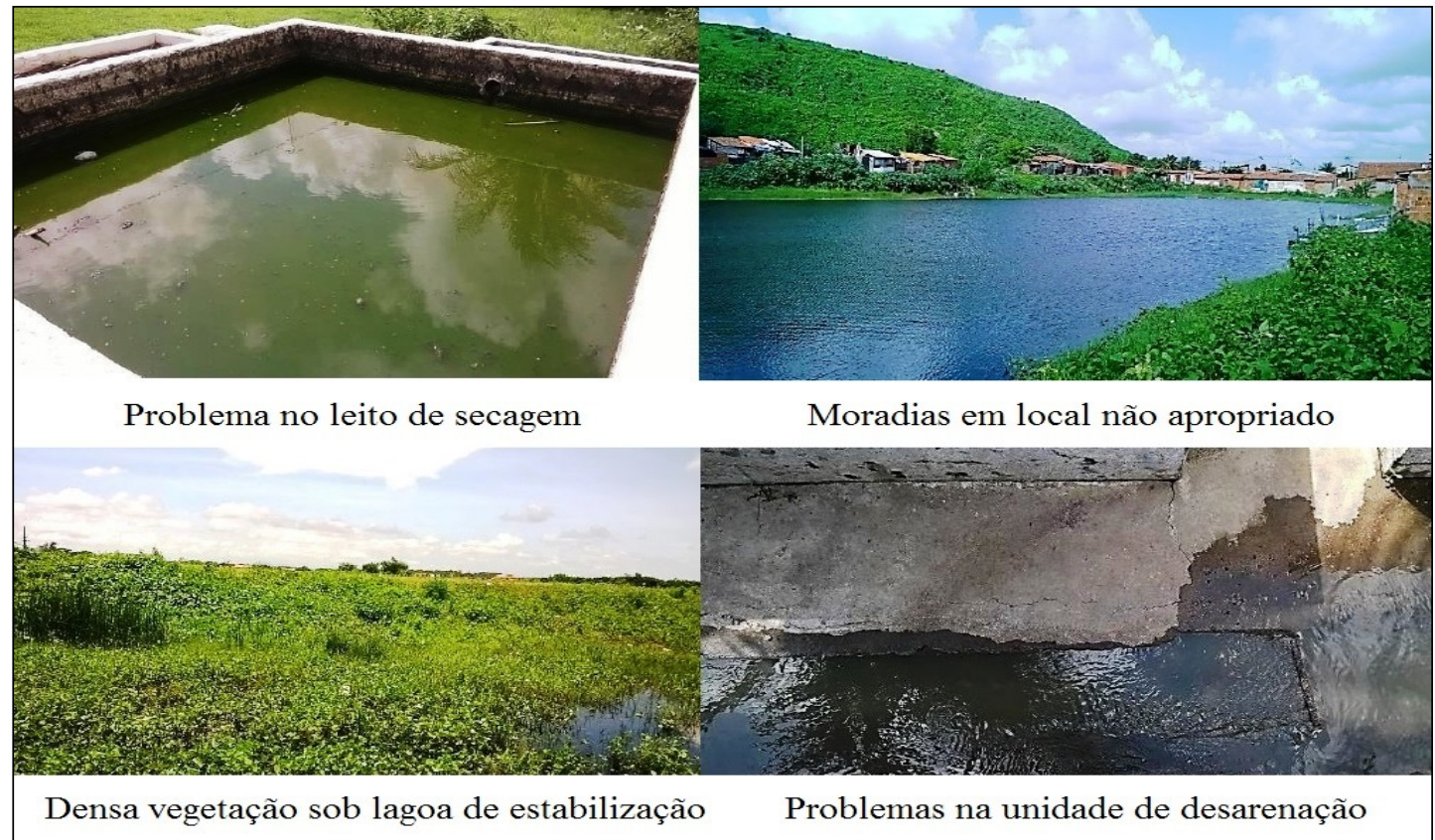

Fonte: Magalhães (2017)

\subsubsection{Critérios Sociais}

A composição dos critérios sociais a fim de avaliar a correlação entre a vulnerabilidade socioambiental e a operação das ETEs foi baseada em um estudo realizado pela Secretaria Municipal de Desenvolvimento Econômico (SDE) da Pre- feitura de Fortaleza, que tem como base os dados do Censo Demográfico do IBGE realizado no ano de 2010 para todos os bairros existentes na capital. Os critérios avaliados foram:

- Índice de Desenvolvimento Humano dos Bairros (IDHB). 
- \% de domicílios ligados à rede de água (no bairro em que a ETE está inserida).

- \% de domicílios ligados à rede de esgoto (no bairro em que a rede está inserida).

\subsection{Definição das Alternativas}

De acordo com Gomes e Gomes (2014), uma ação, ou alternativa, constitui uma das possibilidades de escolha do agente de decisão, identificada no início, ou mesmo no decorrer de um processo decisório, podendo vir a tornar-se uma solução para o problema em estudo.

A seleção das alternativas dependeu diretamente da disponibilidade - por parte da CAGECE ou da
Prefeitura de Fortaleza - de uma série histórica mínima de amostras referentes aos dados qualitativos relacionados aos padrões de qualidade do efluente tratado pela ETE, conforme exigido pela Portaria SEMACE n $154 / 2002$, para que se pudesse alimentar o modelo de apoio à decisão a ser criado, neste caso ao que se refere aos quatro critérios da classe ambiental. Uma vez verificada a impossibilidade de obtenção - ou até mesmo a sua inexistência - destas informações a contento, não foi possível integrar algumas ETEs ao escopo da pesquisa.

Assim, foram selecionadas cinco ETEs que contemplam a sub-bacia do Siqueira e que compõem o escopo deste estudo. Essas ETEs estão identificadas na Tabela 3 a seguir:

Tabela 3 - Identificação das ETES

\begin{tabular}{|c|c|c|c|}
\hline Alternativa & ETE & Descrição & Endereço \\
\hline $\mathrm{A} 1$ & Conjunto Ceará & $\begin{array}{l}\text { Estação de tratamento composta por grade, caixa } \\
\text { de areia, calha Parshall, poço de sucção, } 03 \text { bombas } \\
\text { submersíveis, com } 03 \text { lagoas facultativas em paralelo. }\end{array}$ & Av. E, 460 - Conj. Ceará \\
\hline $\mathrm{A} 2$ & Conjunto Esperança & $\begin{array}{l}\text { Estação de tratamento de pequeno porte com } 01 \text { lagoa } \\
\text { facultativa. }\end{array}$ & Rua Paranaguá s/n \\
\hline $\mathrm{A} 3$ & Novo Mondubim II & $\begin{array}{c}\text { Estação de tratamento composta por grade, poço de } \\
\text { sucção, } 02 \text { bombas submersíveis, com } 01 \text { reator UASB } \\
\text { e cloro (granulado). }\end{array}$ & $\begin{array}{l}\text { Trav. Melquides, } 264 \text { - } \\
\text { Mondubim }\end{array}$ \\
\hline A4 & Parque Fluminense & $\begin{array}{l}\text { Estação de tratamento composta por grade, caixa } \\
\text { de areia, calha Parshall, poço de sucção, } 02 \text { bombas } \\
\text { instaladas em poço seco, com } 01 \text { lagoa anaeróbia } \\
\text { seguida de } 01 \text { facultativa e } 01 \text { maturação, em série. }\end{array}$ & $\begin{array}{l}\text { Rua Cagila Sousa, s/n (esq. } \\
\text { Rua K) - Pq. Santa Rosa } \\
\text {-Mondubim }\end{array}$ \\
\hline A5 & Sumaré & $\begin{array}{l}\text { Estação de tratamento composta por grade, caixa de } \\
\text { poço de sucção, } 02 \text { bombas submersíveis, e sistema de } \\
\text { tratamento em paralelo de } 4 \text { decanto-digestores e } 4 \\
\text { filtros anaeróbios e cloro (granulado). }\end{array}$ & $\begin{array}{l}\text { Rua Nilton Montenegro, } \\
550 \text { - Canindezinho }\end{array}$ \\
\hline
\end{tabular}

\subsection{Definição da problemática}

A definição do tipo de problemática é uma etapa relevante na estruturação do processo, pois pode-se compreender melhor o tipo de problema em questão. Roy (1996) define quatro tipos de problemática: escolha, descritiva, classificação e ordenação.

Neste estudo de caso, a problemática abordada é a de ordenação ou hierarquia, de tal modo que o principal objetivo do trabalho é hierarquizar a intervenção nas ETEs. Esse tipo de problemática consiste em apresentar o problema em termos de ordenação das alternativas, da mais preferida para a menos preferida, de forma a ser possível determinar quais possam ser consideradas desejáveis ou suficientemente satisfatórias. 


\subsection{Escolha do Método Multicritério}

Segundo Magalhães (2017), a escolha de um método de apoio à decisão deve ser embasada pelas características básicas do problema, como o tipo de problemática, os tipos de critérios e de alternativas, as formas com que as informações ao longo do processo decisório podem ser obtidas e os tipos de resultados esperados.

Seguindo essas premissas básicas, o decisor pode se deparar ainda com mais de um método disponível, uma vez que se sabe da grande variedade de métodos multicriteriais já amplamente utilizados pela comunidade cientifica. Para essa pesquisa, buscou-se um método que:

- Trabalhe com a problemática de hierarquização;

- Seja robusto o suficiente para uma grande quantidade de alternativas e de critérios;

- Estruture formalmente o problema;

- Apresente simplicidade de comparação entre pares;

- Permita checar a consistência dos pesos atribuídos;

- Divida os critérios em hierarquias e correlacione as alternativas com os critérios, permitindo uma fácil compreensão e melhor avaliação do problema e;

- Seja versátil.

Nesse contexto, o método escolhido para a realização desse trabalho foi o Analytic Hierarchy Process (AHP), considerando que ele reúne todos os aspectos desejados.

O método AHP de Auxílio Multicritério à Tomada de Decisão, desenvolvido pelo matemático Thomas L. Saaty em 1977, é uma técnica de análise de decisão e planejamento de múltiplos critérios, e sua aplicação reduz o estudo de sistemas complexos a uma sequência de comparações aos pares de componentes adequadamente identificados.

Segundo Hammond, Keeney e Raiffa (2004), a utilização do AHP começa pela definição do problema de decisão, onde se faz necessário conhecer os valores do tomador de decisão. Depois é preciso decompor o problema em uma hierarquia de critérios definidos e que tenham relevância à meta. A partir do momento em que essa hierarquia lógica está construída, os tomadores de decisão avaliam as alternativas por meio da comparação, de duas a duas, dentro de cada um dos critérios, conforme mostra a Fig. 3.

Figura 3 - Estrutura hierárquica do estudo de caso

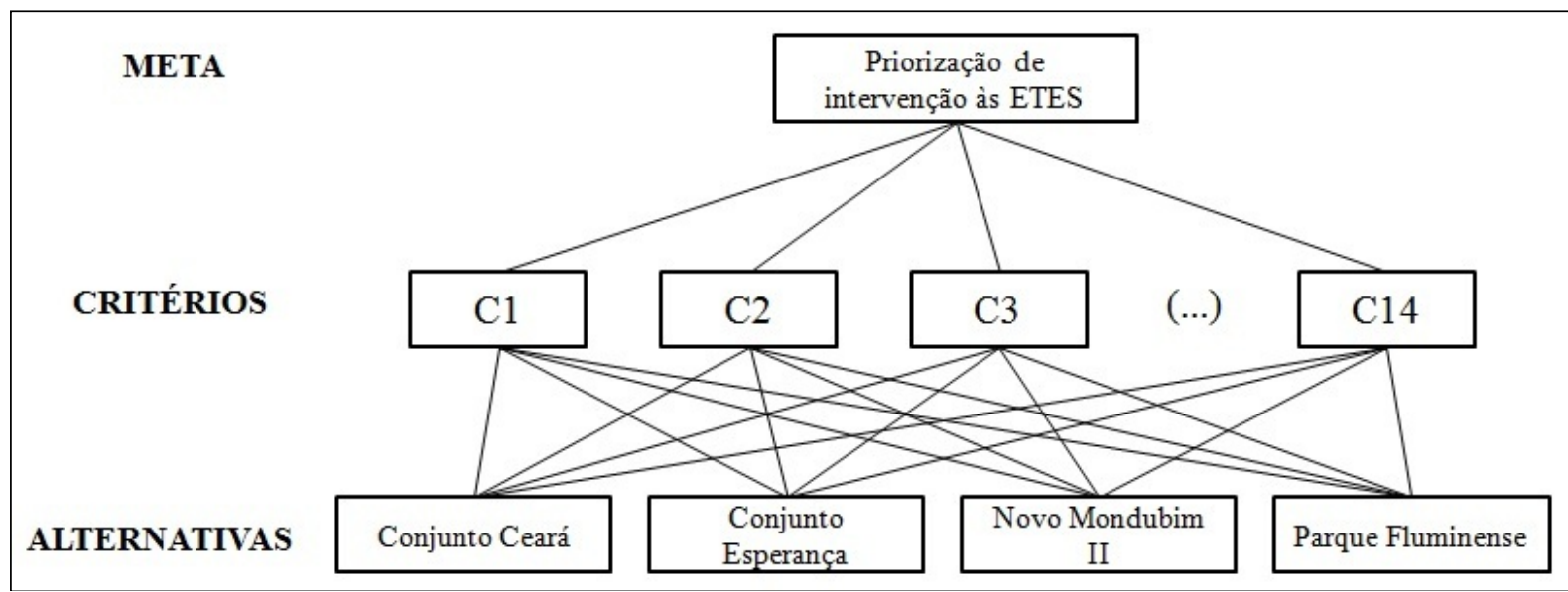

Fonte: Elaborado pela autora (2018) 
Nesse contexto, Saaty (2008) e Chan (2004) elencaram passos a serem seguidos para decompor uma decisão no AHP:

1. Definir o problema e determinar o tipo de conhecimento procurado;

2. Estruturar a hierarquia de decisões a partir do topo, com o objetivo da decisão, nos níveis intermediários (critérios para os quais os elementos subsequentes dependem), para o nível mais baixo (que é geralmente um conjunto de alternativas);

3. Construir um conjunto de matrizes de comparação de pares;

4. Usar as prioridades obtidas das comparações para pesar as prioridades no nível imediatamente abaixo e obter sua prioridade total ou global. Continuar o processo de comparação entre critérios e alternativas;

5. Calcular o índice de consistência $(\mathrm{Cl})$. Se não for satisfatório, refazer os julgamentos.

\section{RESULTADOS E DISCUSSÃO}

A atribuição de peso a critérios e alternativas é determinante no processo de aplicação do método, pois evidencia a influência que as preferências do tomador de decisão exercem através dos pesos atribuídos nos julgamentos.

Para atribuir os pesos aos julgamentos, utiliza-se uma escala fundamental de números absolutos, conhecida por escala Saaty. Mais do que uma escala numérica, baseia-se em aspectos psíquicos que justificam a atribuições de pesos e a utilização de níveis de importância. Trata-se de uma escala verbal (definindo os pesos) apoiada em uma escala cardinal (que denota a intensidade dos pesos), facilitando assim a verificação da melhor alternativa existente. A Tabela 4 apresenta a escala:
Tabela 4 - A Escala de Saaty

\begin{tabular}{|c|c|c|}
\hline $\begin{array}{l}\text { Intensidade da } \\
\text { importância }\end{array}$ & Definição & Explicação \\
\hline 1 & $\begin{array}{l}\text { Igual } \\
\text { importância }\end{array}$ & $\begin{array}{l}\text { Ambos os itens (critérios ou } \\
\text { alternativas) contribuem } \\
\text { igualmente para } \\
\text { atingir o objetivo }\end{array}$ \\
\hline 2 & $\begin{array}{l}\text { Importância } \\
\text { ligeiramente } \\
\text { superior }\end{array}$ & \\
\hline 3 & $\begin{array}{l}\text { Importância } \\
\text { moderada }\end{array}$ & $\begin{array}{c}\text { Experiência e julgamento } \\
\text { favorecem ligeiramente um } \\
\text { item (critérios ou alternativas) } \\
\text { sobre o outro }\end{array}$ \\
\hline 4 & Mais moderada & \\
\hline 5 & $\begin{array}{c}\text { Forte } \\
\text { importância }\end{array}$ & $\begin{array}{l}\text { Experiência e julgamento } \\
\text { favorecem fortemente um } \\
\text { item sobre o outro }\end{array}$ \\
\hline 6 & Mais forte & \\
\hline 7 & $\begin{array}{l}\text { Importância } \\
\text { muito forte }\end{array}$ & $\begin{array}{c}\text { Um item é muito } \\
\text { fortemente favorecido } \\
\text { em detrimento de outro; } \\
\text { sua dominância é demonstrada } \\
\text { na prática }\end{array}$ \\
\hline 8 & Muito mais forte & \\
\hline 9 & $\begin{array}{l}\text { Importância } \\
\text { absoluta } \\
\text { ou extrema } \\
\text { importância }\end{array}$ & $\begin{array}{l}\text { A evidência favorecendo uma } \\
\text { atividade sobre a outra é da mais } \\
\text { alta ordem possível de afirmação }\end{array}$ \\
\hline $\mathrm{n}, 1$ a n,9 & $\begin{array}{c}\text { Quando as } \\
\text { atividade são } \\
\text { muito próximas, } \\
\text { um decimal é } \\
\text { adicionado a } 1 \\
\text { para mostrar a } \\
\text { sua diferença, } \\
\text { conforme } \\
\text { apropriado }\end{array}$ & $\begin{array}{l}\text { Comparar duas atividades } \\
\text { estreitas, favorecendo a maior } \\
\text { com o acréscimo de decimais }\end{array}$ \\
\hline Recíprocos & $\begin{array}{l}\text { Valores inversos } \\
\text { aos pesos de } \\
\text { julgamentos: } \\
(1 / n) \text { onde "n" é } \\
\text { o peso atribuído }\end{array}$ & Suposição lógica \\
\hline
\end{tabular}

Fonte: Adaptado de Saaty (2013)

Nas etapas de comparações paritárias é utilizada a Matriz de Comparação em Pares, também chamada de Matriz de Julgamentos. Godoi (2014) ressalta que a matriz é construída a partir da comparação entre dois itens, entre os critérios existentes bem como entre as alternativas disponíveis. A Tabela 5 a seguir apresenta a matriz de comparação paritária dos critérios do presente trabalho, com base na média das notas atribuídas pelos decisores. 
Tabela 5 - Matriz de Comparação Paritária ou Matriz de Julgamentos

\begin{tabular}{|c|c|c|c|c|c|c|c|c|c|c|c|c|c|c|}
\hline & $\mathrm{C} 1$ & C2 & C3 & C4 & C5 & C6 & C7 & C8 & C9 & C10 & C11 & C12 & C13 & C14 \\
\hline C1 & 1 & $1 / 5$ & $1 / 3$ & $1 / 5$ & $1 / 3$ & $1 / 4$ & $1 / 3$ & $1 / 3$ & $1 / 4$ & 3 & 1 & $1 / 3$ & $1 / 4$ & $1 / 5$ \\
\hline $\mathrm{C2}$ & 5 & 1 & 4 & $1 / 2$ & 4 & 3 & 4 & 4 & 3 & 6 & 5 & 4 & 3 & $1 / 2$ \\
\hline C3 & 3 & $1 / 4$ & 1 & $1 / 4$ & 2 & 3 & 2 & 2 & $1 / 3$ & 4 & 3 & 2 & $1 / 3$ & $1 / 4$ \\
\hline C4 & 5 & 2 & 4 & 1 & 4 & 3 & 4 & 4 & 3 & 6 & 5 & 4 & 3 & 2 \\
\hline C5 & 3 & $1 / 4$ & $1 / 2$ & $1 / 4$ & 1 & $1 / 3$ & 1 & 2 & $1 / 3$ & 4 & 3 & 2 & $1 / 3$ & $1 / 4$ \\
\hline C6 & 4 & $1 / 3$ & $1 / 3$ & $1 / 3$ & 3 & 1 & 3 & 3 & 1 & 5 & 4 & 3 & $1 / 2$ & $1 / 3$ \\
\hline C7 & 3 & $1 / 4$ & $1 / 2$ & $1 / 4$ & 1 & $1 / 3$ & 1 & 2 & $1 / 3$ & 4 & 3 & 2 & $1 / 3$ & $1 / 4$ \\
\hline C8 & 3 & $1 / 4$ & $1 / 2$ & $1 / 4$ & $1 / 2$ & $1 / 3$ & $1 / 2$ & 1 & $1 / 3$ & 4 & 3 & 1 & $1 / 3$ & $1 / 4$ \\
\hline C9 & 4 & $1 / 3$ & 3 & $1 / 3$ & 3 & 1 & 3 & 3 & 1 & 5 & 4 & 3 & $1 / 2$ & $1 / 3$ \\
\hline C10 & $1 / 3$ & $1 / 6$ & $1 / 4$ & $1 / 6$ & $1 / 4$ & $1 / 5$ & $1 / 4$ & $1 / 4$ & $1 / 5$ & 1 & $1 / 3$ & $1 / 4$ & $1 / 5$ & $1 / 6$ \\
\hline C11 & 1 & $1 / 5$ & $1 / 3$ & $1 / 5$ & $1 / 3$ & $1 / 4$ & $1 / 3$ & $1 / 3$ & $1 / 4$ & 3 & 1 & $1 / 3$ & $1 / 4$ & $1 / 5$ \\
\hline C12 & 3 & $1 / 4$ & $1 / 2$ & $1 / 4$ & $1 / 2$ & $1 / 3$ & $1 / 2$ & 1 & $1 / 3$ & 4 & 3 & 1 & $1 / 3$ & $1 / 4$ \\
\hline C13 & 4 & $1 / 3$ & 3 & $1 / 3$ & 3 & 2 & 3 & 3 & 2 & 5 & 4 & 3 & 1 & $1 / 3$ \\
\hline C14 & 5 & 2 & 4 & $1 / 2$ & 4 & 3 & 4 & 4 & 3 & 6 & 5 & 4 & 3 & 1 \\
\hline TOTAL & 44,33 & 7,82 & 22,25 & 4,82 & 26,92 & 18,03 & 26,92 & 29,92 & 15,37 & 60 & 44,33 & 29,92 & 13,37 & 6,32 \\
\hline
\end{tabular}

Fonte: Elaborada pela autora (2018)

Os julgamentos são feitos comparando o elemento linha aos pares respectivos nas colunas. Dessa forma, tem-se que o critério "C1 - $\mathrm{pH}$ " apresenta igual importância (intensidade 1 na Escala de Saaty) sobre o critério "C11-Segurança" e importância moderada (intensidade 3 na escala de Saaty) sobre o critério "C10 - Estado de conservação predial”. As células que apresentam frações representam os julgamentos recíprocos, ou seja, valores apresentados na forma inversa ao peso atribuído na avaliação, de tal forma que se o critério "C2 - Demanda Química de Oxi- gênio" é 5 vezes mais importante que o critério " $\mathrm{C} 1$ - $\mathrm{pH}$ ", logo, “ $\mathrm{C} 1$ - pH" apresentará um quinto da força de "C2 - Demanda Química de Oxigênio". As mesmas análises podem ser realizadas comparando os demais critérios em pares.

Após as comparações paritárias, os julgamentos precisam ser normalizados visando à obtenção do Índice de Consistência (IC). A normalização será obtida pela divisão dos valores de cada peso de julgamento sobre o total apurado para cada coluna. A Tabela 6 mostra os resultados da normalização dos julgamentos:

Tabela 6 - Normalização dos julgamentos

\begin{tabular}{|c|c|c|c|c|c|c|c|c|c|c|c|c|c|c|}
\hline & C1 & C2 & C3 & C4 & C5 & C6 & C7 & C8 & C9 & C10 & C11 & $\mathrm{C} 12$ & C13 & C14 \\
\hline C1 & 0,023 & 0,026 & 0,015 & 0,042 & 0,012 & 0,014 & 0,012 & 0,011 & 0,016 & 0,050 & 0,023 & 0,011 & 0,019 & 0,032 \\
\hline C2 & 0,113 & 0,128 & 0,180 & 0,104 & 0,149 & 0,166 & 0,149 & 0,134 & 0,195 & 0,100 & 0,113 & 0,134 & 0,224 & 0,079 \\
\hline C3 & 0,068 & 0,032 & 0,045 & 0,052 & 0,074 & 0,166 & 0,074 & 0,067 & 0,022 & 0,067 & 0,068 & 0,067 & 0,025 & 0,040 \\
\hline C4 & 0,113 & 0,256 & 0,180 & 0,208 & 0,149 & 0,166 & 0,149 & 0,134 & 0,195 & 0,100 & 0,113 & 0,134 & 0,224 & 0,317 \\
\hline C5 & 0,068 & 0,032 & 0,022 & 0,052 & 0,037 & 0,018 & 0,037 & 0,067 & 0,022 & 0,067 & 0,068 & 0,067 & 0,025 & 0,040 \\
\hline C6 & 0,090 & 0,043 & 0,015 & 0,069 & 0,111 & 0,055 & 0,111 & 0,100 & 0,065 & 0,083 & 0,090 & 0,100 & 0,037 & 0,053 \\
\hline C7 & 0,068 & 0,032 & 0,022 & 0,052 & 0,037 & 0,018 & 0,037 & 0,067 & 0,022 & 0,067 & 0,068 & 0,067 & 0,025 & 0,040 \\
\hline C8 & 0,068 & 0,032 & 0,022 & 0,052 & 0,019 & 0,018 & 0,019 & 0,033 & 0,022 & 0,067 & 0,068 & 0,033 & 0,025 & 0,040 \\
\hline C9 & 0,090 & 0,043 & 0,135 & 0,069 & 0,111 & 0,055 & 0,111 & 0,100 & 0,065 & 0,083 & 0,090 & 0,100 & 0,037 & 0,053 \\
\hline C10 & 0,008 & 0,021 & 0,011 & 0,035 & 0,009 & 0,011 & 0,009 & 0,008 & 0,013 & 0,017 & 0,008 & 0,008 & 0,015 & 0,026 \\
\hline C11 & 0,023 & 0,026 & 0,015 & 0,042 & 0,012 & 0,014 & 0,012 & 0,011 & 0,016 & 0,050 & 0,023 & 0,011 & 0,019 & 0,032 \\
\hline C12 & 0,068 & 0,032 & 0,022 & 0,052 & 0,019 & 0,018 & 0,019 & 0,033 & 0,022 & 0,067 & 0,068 & 0,033 & 0,025 & 0,040 \\
\hline C13 & 0,090 & 0,043 & 0,135 & 0,069 & 0,111 & 0,111 & 0,111 & 0,100 & 0,130 & 0,083 & 0,090 & 0,100 & 0,075 & 0,053 \\
\hline C14 & 0,113 & 0,256 & 0,180 & 0,104 & 0,149 & 0,166 & 0,149 & 0,134 & 0,195 & 0,100 & 0,113 & 0,134 & 0,224 & 0,158 \\
\hline
\end{tabular}


Após a normalização, é preciso determinar a contribuição de cada critério na meta organizacional. Essa contribuição é calculada a partir do chamado Vetor de Prioridade ou Vetor de Eigen. Segundo Vargas (2010), o vetor de Eigen apre- senta os pesos relativos entre os critérios e é obtido de modo aproximado por meio da média aritmética dos valores de cada um dos critérios. O cálculo do vetor para cada um dos critérios em análise é mostrado na Tabela 7.

Tabela 7 - Cálculo do Vetor de Eigen

\begin{tabular}{|c|c|c|c|c|c|c|c|c|c|c|c|c|c|}
\hline C1 & C2 & C3 & C4 & C5 & C6 & C7 & C8 & C9 & C10 & C11 & C12 & C13 & C14 \\
\hline 0,022 & 0,140 & 0,062 & 0,174 & 0,044 & 0,073 & 0,044 & 0,037 & 0,082 & 0,014 & 0,022 & 0,037 & 0,093 & 0,155 \\
\hline \multicolumn{10}{c|}{ Fonte: Elaborado pela autora (2018) }
\end{tabular}

O resultado do cálculo dos vetores de Eigen pode ser interpretado como a participação percentual de cada item avaliado, representando a importância percentual de cada item.

O passo seguinte é a determinação do Número Principal de Eigen, obtido por meio da somatória do produto de cada elemento do vetor de Eigen, conforme cálculos na Tabela 7 anterior, multiplicados pelo total de cada coluna calculado na Tabela 5. Considerando os valores apresentados, tem-se:

$(0,022 * 44,33)+(0,140 * 7,82)+(0,062 * 22,25)+$ $(0,174 * 4,82)+(0,044 * 26,92)+(0,073 * 18,03)+$ $(0,044 * 26,92)+(0,037 * 29,92)+(0,082 * 15,37)$ $+(0,014 * 60)+(0,022 * 44,33)+(0,037 * 29,92)+$ $(0,093 * 13,37)+(0,155 * 6,32)=15,490$

Com esses valores é possível determinar o Índice de Consistência $(\mathrm{Cl})$, que conforme Saaty (2013) é obtido pela Eq. 1:

$\mathrm{Cl}=\frac{\measuredangle \mathrm{máx}-n}{n-1}$

Onde:

$\mathrm{Cl}$ - Índice de Consistência, do inglês Consistency Index.
$\Lambda_{\text {máx }}-$ Maior autovetor da matriz, equivalente ao $\mathrm{n}^{\circ}$ principal de Eigen.

$\mathrm{n}$ - número de elementos da matriz.

No presente estudo de caso temos:

$\mathrm{Cl}=\frac{15,49-14}{14-1}=0,11$

O valor obtido como Índice de Consistência (Cl) será utilizado na obtenção da Taxa de Consciência, do inglês Consistency Ratio (CR). A Taxa de Consistência é determinada pela razão entre o $\mathrm{Cl}$ e o Índice de Consistência Aleatória, do inglês Random Inconsistency (RI). Segundo Vargas (2010), a matriz será considerada consistente se a razão for menor que $10 \%$, conforme mostra a Eq. 2:

$$
\mathrm{CR}=\frac{C I}{R I}<0,1 \sim 10 \%
$$

O valor de RI pode ser observado na Tabela 8 a seguir, que relaciona o número de elementos da matriz com valores fixos usados como referência e calculados em laboratório.

Tabela 8 - Índices de Consistência Aleatória

\begin{tabular}{|c|c|c|c|c|c|c|c|c|c|c|c|c|c|c|c|}
\hline$n$ & 1 & 2 & 3 & 4 & 5 & 6 & 7 & 8 & 9 & 10 & 11 & 12 & 13 & 14 & 15 \\
\hline RI & 0.00 & 0.00 & 0.58 & 0.90 & 1.12 & 1.24 & 1.32 & 1.41 & 1.45 & 1.49 & 1.51 & 1.48 & 1.56 & 1.57 & 1.59 \\
\hline
\end{tabular}


No estudo em análise, há quatorze critérios, logo o valor de RI utilizado será 1,57. Portanto:

$\mathrm{CR}=\frac{0,11}{1,57}=0,07=7 \%$

Observa-se que $C R<0,1$. A matriz de julgamentos é consistente.

O processo de julgamentos paritários é fundamental para o sucesso de uma análise pelo método AHP. No entanto, a comparação em pares impede muitas vezes que todo o conjunto de itens avaliados (critérios e alternativas) seja considerado. Nesse contexto, a fim de auxiliar o tomador de decisão a ter uma visão mais completa do projeto em análise, surge o conceito de julgamento holístico, pautado na observação a partir do todo.

Nesta etapa foram construídas matrizes comparando todas as alternativas tendo como norteador cada um dos critérios escolhidos. Dessa forma, o decisor foi orientado a atribuir pesos conforme a força da alternativa diante das demais, pautando-se pelo critério norteador. As Eq.
3 e 4 a seguir mostram como são atribuídos os julgamentos:

Se RJ > J. $\therefore(R J-J)+1$

Se RJ $<J: \therefore 1 /[(J-R J)+1]$

Em que:

RJ - referência de julgamento (elemento linha na matriz de comparação paritária);

J - julgado (elemento coluna na matriz de comparação paritária).

Segundo Godoi (2014), no julgamento holístico deve-se atribuir peso aos itens e utilizar as fórmulas para construção dos julgamentos na matriz de julgamentos paritários para então proceder às análises de consistência e verificação da melhor alternativa.

Nesse contexto, seguem as etapas de execução do julgamento holístico para esse estudo de caso. A Tabela 9 apresenta os pesos e a Tabela 10 apresenta o julgamento holístico dos critérios.

Tabela 9 - Pesos dos Critérios

\begin{tabular}{|c|c|c|c|c|c|c|c|c|c|c|c|c|c|c|}
\hline & C1 & C2 & C3 & C4 & C5 & C6 & C7 & C8 & C9 & C10 & C11 & C12 & C13 & C14 \\
\hline PESO & 6 & 9 & 7 & 9 & 7 & 8 & 7 & 7 & 8 & 5 & 6 & 7 & 8 & 9 \\
\hline
\end{tabular}

Tabela 10 - Julgamento holístico dos critérios

\begin{tabular}{|c|c|c|c|c|c|c|c|c|c|c|c|c|c|c|}
\hline & C1 & C2 & C3 & C4 & C5 & C6 & C7 & C8 & C9 & C10 & C11 & C12 & C13 & C14 \\
\hline C1 & 1 & 0,25 & 0,5 & 0,25 & 0,5 & 0,33 & 0,5 & 0,5 & 0,33 & 2 & 1 & 0,5 & 0,33 & 0,25 \\
\hline $\mathrm{C} 2$ & 4 & 1 & 3 & 1 & 3 & 2 & 3 & 3 & 2 & 5 & 4 & 3 & 2 & 1 \\
\hline C3 & 2 & 0,33 & 1 & 0,33 & 1 & 0,5 & 1 & 1 & 0,5 & 3 & 2 & 1 & 0,5 & 0,33 \\
\hline C4 & 4 & 1 & 3 & 1 & 3 & 2 & 3 & 3 & 2 & 5 & 4 & 3 & 2 & 1 \\
\hline C5 & 2 & 0,33 & 1 & 0,33 & 1 & 0,5 & 1 & 1 & 0,5 & 3 & 2 & 1 & 0,5 & 0,33 \\
\hline C6 & 3 & 0,5 & 2 & 0,5 & 2 & 1 & 2 & 2 & 1 & 4 & 3 & 2 & 1 & 0,5 \\
\hline C7 & 2 & 0,33 & 1 & 0,33 & 1 & 0,5 & 1 & 1 & 0,5 & 3 & 2 & 1 & 0,5 & 0,33 \\
\hline C8 & 2 & 0,33 & 1 & 0,33 & 1 & 0,5 & 1 & 1 & 0,5 & 3 & 2 & 1 & 0,5 & 0,33 \\
\hline C9 & 3 & 0,5 & 2 & 0,5 & 2 & 1 & 2 & 2 & 1 & 4 & 3 & 2 & 1 & 0,5 \\
\hline C10 & 0,5 & 0,2 & 0,33 & 0,2 & 0,33 & 0,25 & 0,33 & 0,33 & 0,25 & 1 & 0,5 & 0,33 & 0,25 & 0,2 \\
\hline C11 & 1 & 0,25 & 0,5 & 0,25 & 0,5 & 0,33 & 0,5 & 0,5 & 0,33 & 2 & 1 & 0,5 & 0,33 & 0,25 \\
\hline C12 & 2 & 0,33 & 1 & 0,33 & 1 & 0,5 & 1 & 1 & 0,5 & 3 & 2 & 1 & 0,5 & 0,33 \\
\hline C13 & 3 & 0,5 & 2 & 0,5 & 2 & 1 & 2 & 2 & 1 & 4 & 3 & 2 & 1 & 0,5 \\
\hline C14 & 4 & 1 & 3 & 1 & 3 & 2 & 3 & 3 & 2 & 5 & 4 & 3 & 2 & 1 \\
\hline
\end{tabular}


Repetindo o procedimento para o cálculo da Taxa de Consistência, temos que:

$$
C R=0,0075
$$

Como $\mathrm{CR}<0,1$, os pesos atribuídos na matriz de julgamento dos critérios se mostraram consistentes.
A partir disso, o julgamento holístico foi aplicado a cada uma das alternativas existentes, seguindo o mesmo roteiro da etapa descrita anteriormente. A Tabela 11 mostra os pesos das alternativas atribuídos pelos decisores, em relação a cada critério.

Tabela 11 - Pesos das alternativas em relação aos critérios

\begin{tabular}{|c|c|c|c|c|c|}
\hline $\begin{array}{l}\text { ALTERNATIVAS } \\
\text { CRITÉRIOS }\end{array}$ & Conjunto Ceará & $\begin{array}{l}\text { Conjunto } \\
\text { Esperança }\end{array}$ & $\begin{array}{c}\text { Novo } \\
\text { Mondubim II }\end{array}$ & $\begin{array}{l}\text { Parque } \\
\text { Fluminense }\end{array}$ & Sumaré \\
\hline $\mathrm{pH}$ & 8 & 7 & 8 & 5 & 7 \\
\hline Demanda Química de Oxigênio & 6 & 5 & 9 & 3 & 7 \\
\hline Sólidos Suspensos Totais & 6 & 7 & 9 & 1 & 6 \\
\hline E. coli & 9 & 9 & 3 & 8 & 7 \\
\hline Mau desempenho da unidade de desarenação & 3 & 6 & 2 & 6 & 4 \\
\hline Maus odores & 3 & 6 & 2 & 5 & 4 \\
\hline Descarte inadequado de lodo & 3 & 6 & 2 & 6 & 4 \\
\hline Assoreamento ou presença de resíduos sólidos & 3 & 6 & 2 & 6 & 4 \\
\hline Problemas no estado de conservação das unidades & 3 & 6 & 2 & 5 & 4 \\
\hline Problemas no estado de conservação predial & 4 & 8 & 3 & 7 & 5 \\
\hline Problemas de segurança & 4 & 6 & 2 & 6 & 4 \\
\hline IDH dos bairros & 5 & 4 & 3 & 3 & 2 \\
\hline \% domicílios ligados à rede de água & 9 & 6 & 3 & 3 & 2 \\
\hline \% domicílios ligados à rede de esgoto & 9 & 7 & 7 & 7 & 8 \\
\hline
\end{tabular}

O desenvolvimento do julgamento holístico das alternativas em relação ao critério pH está presente na Tabela 12, assim como o valor calculado da sua Taxa Consistência (CR).

Tabela 12 - Julgamento holístico das alternativas - Critério: pH

\begin{tabular}{|c|c|c|c|c|c|}
\hline pH & Conjunto Ceará & $\begin{array}{c}\text { Conjunto } \\
\text { Esperança }\end{array}$ & $\begin{array}{c}\text { Novo } \\
\text { Mondubim II }\end{array}$ & $\begin{array}{c}\text { Parque } \\
\text { Fluminense }\end{array}$ & Sumaré \\
\hline Conjunto Ceará & 1 & 2 & 1 & 4 & 2 \\
\hline Conjunto Esperança & 0,5 & 1 & 0,5 & 3 & 1 \\
\hline Novo Mondubim II & 1 & 2 & 1 & 4 & 2 \\
\hline Parque Fluminense & 0,25 & 0,33 & 0,25 & 1 & 0,33 \\
\hline Sumaré & 0,5 & 1 & 0,5 & 3 & 1 \\
\hline & \multicolumn{2}{|c|}{$\mathbf{C R}=\mathbf{0 , 0 0 6}$} & & \\
\hline
\end{tabular}

Fonte: Elaborada pela autora (2018)

Repetindo o julgamento das alternativas perante cada um dos critérios, observou-se que todos os valores de taxa de consistência são consistentes, ou seja, possuem $\mathrm{CR}<0,1(10 \%)$.

Para obter a importância final de cada alternativa, foram calculados os pesos relativos das alternativas (Vetor de Eigen) para depois multiplicá-los pelos pesos relativos dos critérios, já calculados na Tabela 7. O valor total é obtido somando-se os resultados dos diferentes passos.

Assim, para a alternativa A1 (Conjunto Ceará), a pontuação final é obtida da seguinte forma: 
$(0,303 * 0,022)+(0,147 * 0,140)+(0,136 * 0,062)+$

$(0,324 * 0,174)+(0,091 * 0,044)+(0,099 * 0,073)+$ $(0,091 * 0,044)+(0,091 * 0,037)+(0,099 * 0,082)+$ $(0,083 * 0,014)+(0,130 * 0,022)+(0,402 * 0,037)+$ $(0,557 * 0,093)+(0,394 * 0,155)=\mathbf{0 , 2 5 1}$

Procedendo da mesma forma para as demais alternativas, obtemos a Matriz de Decisão a seguir, que mostra o peso atribuído a cada critério, o desempenho das alternativas em relação a cada critério e o total (resultado) que corresponde ao somatório das multiplicações entre o peso de cada critério e o respectivo desempenho das alternativas naquele critério:

Tabela 13 - Matriz de Decisão

\begin{tabular}{|c|c|c|c|c|c|c|c|c|c|c|c|c|c|c|c|}
\hline & $\begin{array}{c}\text { C1 } \\
0,022\end{array}$ & $\begin{array}{c}C 2 \\
0,140\end{array}$ & $\begin{array}{c}\text { C3 } \\
0,062\end{array}$ & $\begin{array}{c}\text { C4 } \\
0,174\end{array}$ & $\begin{array}{c}\text { C5 } \\
0,044\end{array}$ & $\begin{array}{c}\text { C6 } \\
0,073\end{array}$ & $\begin{array}{c}\text { C7 } \\
0,044\end{array}$ & $\begin{array}{c}\text { C8 } \\
0,037\end{array}$ & $\begin{array}{c}\text { C9 } \\
0,082\end{array}$ & $\begin{array}{c}\text { C10 } \\
0,014\end{array}$ & $\begin{array}{c}\text { C11 } \\
0,022\end{array}$ & $\begin{array}{c}\text { C12 } \\
0,037\end{array}$ & $\begin{array}{c}\text { C13 } \\
0,093\end{array}$ & $\begin{array}{c}\text { C14 } \\
0,155\end{array}$ & Total \\
\hline A1 & 0,303 & 0,147 & 0,136 & 0,324 & 0,091 & 0,099 & 0,091 & 0,091 & 0,099 & 0,083 & 0,130 & 0,402 & 0,557 & 0,394 & 0,251 \\
\hline$A 2$ & 0,165 & 0,094 & 0,219 & 0,324 & 0,352 & 0,416 & 0,352 & 0,352 & 0,416 & 0,441 & 0,342 & 0,244 & 0,239 & 0,124 & 0,260 \\
\hline A3 & 0,303 & 0,485 & 0,478 & 0,037 & 0,058 & 0,062 & 0,058 & 0,058 & 0,062 & 0,054 & 0,056 & 0,137 & 0,078 & 0,124 & 0,161 \\
\hline A4 & 0,065 & 0,045 & 0,031 & 0,192 & 0,352 & 0,262 & 0,352 & 0,352 & 0,262 & 0,291 & 0,342 & 0,137 & 0,078 & 0,124 & 0,171 \\
\hline A5 & 0,165 & 0,229 & 0,136 & 0,123 & 0,146 & 0,161 & 0,146 & 0,146 & 0,161 & 0,131 & 0,130 & 0,079 & 0,048 & 0,234 & 0,157 \\
\hline Soma & 1,000 & 1,000 & 1,000 & 1,000 & 1,000 & 1,000 & 1,000 & 1,000 & 1,000 & 1,000 & 1,000 & 1,000 & 1,000 & 1,000 & 1,000 \\
\hline
\end{tabular}

Dos valores totais da Matriz de Decisão, é possível obter o ordenamento de priorização de intervenção às ETEs, ranqueando as estações em ordem de maior prioridade, conforme exibido na Tabela 14.

Tabela 14 - Hierarquização de intervenção às ETEs

\begin{tabular}{|c|c|c|}
\hline $\begin{array}{c}\text { Ordem } \\
1^{\circ}\end{array}$ & A2 - Conjunto Esperança & 0,260 \\
\hline $2^{\circ}$ & A1 - Conjunto Ceará & 0,251 \\
\hline $3^{\circ}$ & A4 - Parque Fluminense & 0,171 \\
\hline $4^{\circ}$ & A3 - Novo Mondubim II & 0,161 \\
\hline $5^{\circ}$ & A5 - Sumaré & 0,157 \\
\hline \multicolumn{3}{|c|}{ Fonte: Elaborada pela autora (2018) } \\
\hline
\end{tabular}

Da análise da hierarquização das ETEs, observase que o melhor desempenho foi da alternativa A2 (Conj. Esperança) com 26,0\%; que, comparativamente com os desempenhos das demais alternativas, pode ser considerado um resultado pouco robusto neste primeiro momento, indicando que as alternativas que estão sendo estudadas possuem atributos semelhantes.

Diante disso, é importante examinar quão sensível é a alternativa escolhida se as variáveis envolvidas no modelo de decisão forem alteradas. Isso ajuda o tomador de decisão a visualizar possíveis caminhos em eventuais situações não previstas.

Nesse contexto, a Análise de Sensibilidade surge como uma ferramenta de análise mais crítica, pois considera a sensibilidade do valor da variável dependente devido a mudanças dos valores das variáveis independentes. Para este estudo de caso, a Análise de Sensibilidade foi realizada da seguinte forma: os valores dos pesos atribuídos para cada uma das alternativas em relação aos critérios ambientais foram completamente alterados, conforme mostra a Tabela 15. Os julgamentos dos demais critérios permanecem iguais. 
Tabela 15 - Análise de Sensibilidade: Variações de julgamentos - Critérios ambientais

\begin{tabular}{|c|c|c|c|c|c|}
\hline $\begin{array}{l}\text { ALTERNATIVAS } \\
\text { CRITÉRIOS }\end{array}$ & Conjunto Ceará & $\begin{array}{l}\text { Conjunto } \\
\text { Esperança }\end{array}$ & $\begin{array}{c}\text { Novo } \\
\text { Mondubim II }\end{array}$ & $\begin{array}{l}\text { Parque } \\
\text { Fluminense }\end{array}$ & Sumaré \\
\hline $\mathrm{pH}$ & 8 & 7 & 8 & 5 & 7 \\
\hline Demanda Química de Oxigênio & 6 & 5 & 9 & 3 & 7 \\
\hline Sólidos Suspensos Totais & 6 & 7 & 9 & 1 & 6 \\
\hline E. coli & 9 & 9 & 3 & 8 & 7 \\
\hline Mau desempenho da unidade de desarenação & 3 & 6 & 2 & 6 & 4 \\
\hline Maus odores & 3 & 6 & 2 & 5 & 4 \\
\hline Descarte inadequado de lodo & 3 & 6 & 2 & 6 & 4 \\
\hline Assoreamento ou presença de resíduos sólidos & 3 & 6 & 2 & 6 & 4 \\
\hline Problemas no estado de conservação das unidades & 3 & 6 & 2 & 5 & 4 \\
\hline Problemas no estado de conservação predial & 4 & 8 & 3 & 7 & 5 \\
\hline Problemas de segurança & 4 & 6 & 2 & 6 & 4 \\
\hline IDH dos bairros & 5 & 4 & 3 & 3 & 2 \\
\hline \% domicílios ligados à rede de água & 9 & 6 & 3 & 3 & 2 \\
\hline \% domicílios ligados à rede de esgoto & 9 & 7 & 7 & 7 & 8 \\
\hline
\end{tabular}

Observa-se que a Tabela 14 surge a partir da substituição dos novos pesos na Tabela 11. A Tabela 16 mostra a nova Matriz de Decisão e a Tabela 17 o resultado da nova hierarquia, ambas obtidas a partir dos novos julgamentos.

Tabela 16 - Análise de Sensibilidade: Matriz de Decisão

\begin{tabular}{|c|c|c|c|c|c|c|c|c|c|c|c|c|c|c|c|}
\hline & $\begin{array}{c}\text { C1 } \\
0,022\end{array}$ & $\begin{array}{c}\text { C2 } \\
0,140\end{array}$ & $\begin{array}{c}\text { C3 } \\
0,062\end{array}$ & $\begin{array}{c}\text { C4 } \\
0,174\end{array}$ & $\begin{array}{c}\text { C5 } \\
0,044\end{array}$ & $\begin{array}{c}\text { C6 } \\
0,073\end{array}$ & $\begin{array}{c}\text { C7 } \\
0,044\end{array}$ & $\begin{array}{c}\text { C8 } \\
0,037\end{array}$ & $\begin{array}{c}\text { C9 } \\
0,082\end{array}$ & $\begin{array}{c}\text { C10 } \\
0,014\end{array}$ & $\begin{array}{c}\text { C11 } \\
0,022\end{array}$ & $\begin{array}{c}\text { C12 } \\
0,037\end{array}$ & $\begin{array}{c}\text { C13 } \\
0,093\end{array}$ & $\begin{array}{c}\text { C14 } \\
0,155\end{array}$ & Total \\
\hline A1 & 0,062 & 0,042 & 0,215 & 0,485 & 0,091 & 0,099 & 0,091 & 0,091 & 0,099 & 0,083 & 0,130 & 0,402 & 0,557 & 0,394 & 0,263 \\
\hline A2 & 0,042 & 0,273 & 0,343 & 0,089 & 0,352 & 0,416 & 0,352 & 0,352 & 0,416 & 0,441 & 0,342 & 0,244 & 0,239 & 0,124 & 0,249 \\
\hline A3 & 0,132 & 0,177 & 0,343 & 0,227 & 0,058 & 0,062 & 0,058 & 0,058 & 0,062 & 0,054 & 0,056 & 0,137 & 0,078 & 0,124 & 0,139 \\
\hline A4 & 0,260 & 0,425 & 0,065 & 0,057 & 0,352 & 0,262 & 0,352 & 0,352 & 0,262 & 0,291 & 0,342 & 0,137 & 0,078 & 0,124 & 0,207 \\
\hline A5 & 0,504 & 0,084 & 0,034 & 0,143 & 0,146 & 0,161 & 0,146 & 0,146 & 0,161 & 0,131 & 0,130 & 0,079 & 0,048 & 0,234 & 0,142 \\
\hline Soma & 1,000 & 1,000 & 1,000 & 1,000 & 1,000 & 1,000 & 1,000 & 1,000 & 1,000 & 1,000 & 1,000 & 1,000 & 1,000 & 1,000 & 1,000 \\
\hline
\end{tabular}

Fonte: Elaborada pela autora (2018)

Tabela 17 - Análise de Sensibilidade: Hierarquização de intervenção às ETEs

\begin{tabular}{|c|c|c|}
\hline $\begin{array}{c}\text { Ordem } \\
1^{\circ}\end{array}$ & A1 - Conjunto Ceará & 0,263 \\
\hline $2^{\circ}$ & A2 - Conjunto Esperança & 0,249 \\
\hline $3^{\circ}$ & A4 - Parque Fluminense & 0,207 \\
\hline $4^{\circ}$ & A5 - Sumaré & 0,142 \\
\hline $5^{\circ}$ & A3 - Novo Mondubim II & 0,139 \\
\hline \multicolumn{3}{|c|}{ Fonte: Elaborada pela autora (2018) } \\
\hline
\end{tabular}

Após a Análise de Sensibilidade é possível perceber uma mudança na hierarquia das ETEs, porém as alternativas $A 1$ e $A 2$ se mantiveram com melhor desempenho em relação às demais, mostrando que dentre as alternativas elas devem possuir prioridade de intervenção. Dessa forma, segundo as preferências do decisor, a hierarquia a ser considerada como resultado final desse trabalho é a descrita na Tabela 14.

\section{CONCLUSÃO}

Naturalmente, o presente artigo sofre as limitações comuns à descrição de uma longa pesquisa conceitual que necessita ser sintetizada em poucas linhas. Porém, a partir de seu caráter exploratório, é possível afirmar que o ordenamento para priorização de intervenção às ETEs que apresen- 
tem desconformidades de naturezas diversas mostrou ser uma problemática passível de resolução a partir de uma metodologia multicritério de apoio à decisão.

A utilização do método AHP revelou-se como uma ferramenta matemática de fácil reprodutibilidade, transformando informações essencialmente quantitativas em informações que permitiram estabelecer uma relevância entre uma alternativa e outra a partir da escala de Saaty, possibilitando a elaboração da estrutura hierárquica e facilitando o processo decisório. A qualidade das avaliações realizadas pelos tomadores de decisão foi um aspecto importante, pois a coerência das respostas pôde ser calculada pelo índice de inconsistência, permitindo a avaliação da consistência e a regularidade das opiniões dos decisores.

Um aspecto negativo é que a análise multicritério é altamente sensível às variações de julgamentos de valor realizadas; pequenas alterações nos valores da decisão podem alterar completamente os resultados obtidos. Por isso, é importante lembrar-se do caráter recomendativo da metodologia aplicada. Assim, durante uma possível adoção dos resultados gerados para o ordenamento de priorização de intervenção nas ETEs, pode ainda existir alterações segundo fatores externos aos compilados pelos critérios propostos.

No mais, a metodologia proposta conseguiu integrar a conjuntura complexa que envolve critérios ambientais, operacionais e sociais, consensualmente validados por todos os representantes das classes de decisores. Considerase, então, que os objetivos do trabalho foram atingidos e a metodologia multicritério tornou possível estruturar o processo de decisão de forma racional e transparente.

\section{CONTRIBUIÇÃO DOS AUTORES}

Todos os autores contribuíram de forma igualitária.

\section{REFERÊNCIAS}

BOUYSSOU, D. Building criteria: A pre requisite for MCDA. In: C.A. Bana e Costa, editor, Readings in Multiple Criteria Decision Aid, pages 58-80. Springer-Verlag, Berlin, 1990.

BRANS, J.P.; MARESCHAL, B.; The promethee-gaia decision support system for multicriterial investigation. In: Proceedings of the international conference in multiple decision making. Coimbra, 1994.

BRASIL. Guia para a elaboração de planos municipais de saneamento. BERNARDES, R. S; SCÁRDUA, M. P; CAMPANA, N. A. (Org.). Brasília: Ministério das Cidades, 2006b.

BRASIL. Ministério das Cidades. Secretaria Nacional de Saneamento Ambiental - SNSA. Sistema Nacional de Informações sobre Saneamento: Diagnóstico dos Serviços de Água e Esgotos - 2016. Brasília: SNSA/MCIDADES, 2018. 220 p.

BUNRUAMKAEW, K. How to do AHP Analysis in Excel. Division of Spatial Information Science. Graduate School of Life and Environmental Sciences. University of Tsukuba. 2012.

CAGECE. Esgoto. 2018. Disponível em: <https://www.cagece. com.br/produtos-e-servicos/esgoto/>. Acesso em: 20 dez. 2018.

CAMPOS, V. R.; ALMEIDA, A. T. Modelo multicritério de decisão para localização de Nova Jaguaribara com Vip Analysis. Pesqui. Oper., Rio de Janeiro, v. 26, n. 1, p. 91-107, 2006. https://doi. org/10.1590/S0101-74382006000100005

CARLEIAL, A. N.; ARAÚJO, A. M. M. (Org.). Atlas de Fortaleza 2000. Fortaleza: EdUECE, 2010.

CHAN, A H.S., KWOK, W.Y., DUFFY, V. G. Using AHP for determining priority in a safety management system. Industrial Management \& Data Systems, v. 104, n. 5, p 430-445, 2004. https://doi. org/10.1108/02635570410537516

ENSSLIN, L.; MONTIBELLER, G. N.; NORONHA, S. M. Apoio à decisão: Metodologias para Estruturação de Problemas e Avaliação Multicritério de Alternativas. Florianópolis, 2001.

FORTALEZA. Prefeitura de Fortaleza. Diagnóstico das atuais condições de drenagem do município de Fortaleza. Plano Municipal De Saneamento Básico de Fortaleza. 2013a.

Prefeitura Municipal de Fortaleza. Secretaria Municipal de Desenvolvimento Econômico. Desenvolvimento humano, por bairro, em Fortaleza. 2013b.

Prefeitura de Fortaleza. Prognóstico dos serviços de esgotamento sanitário. Plano Municipal De Saneamento Básico de Fortaleza. 2013c.

GODOI, W. C. Método De Construção Das Matrizes De Julgamento Paritários No Ahp - Método Do Julgamento Holístico. Revista Gestão Industrial, v. 10, $n^{\circ}$ 3, p. 474-493, 2014. GOMES, L. F. A. M.; GOMES, C. F. S. Tomada de decisão gerencial: enfoque multicritério. $5^{a}$ Ed. São Paulo: Atlas, 2014. https://dx.doi.org/10.3895/ S1808-04482014000300001 
HAMMOND, J.S.; KEENEY, R. L.; RAIFFA, H. Decisões inteligentes: somos movidos a decisões - como avaliar alternativas e tomar a melhor decisão. Tradução: Marcelo Filardi Ferreira. Rio de Janeiro: Elsevier, 2004. 228 p. Tradução de: Smartchoices.

IBGE. Instituto Brasileiro de Geografia e Estatística. Cidades. Infográficos: despesas e receitas orçamentárias e PIB. 2016a. Disponível em: <http://www.cidades.ibge.gov.br/painel/economia. php>. Acesso em: 18 mar. 2016.

MAGALHÃES, A. M. C. Proposta de Metodologia Multicriterial para Priorização de Intervenção em ETEs Segundo Análise da Vulnerabilidade Socioambiental - Estudo de Caso em Fortaleza/CE. 189 f. Dissertação (Mestrado). Universidade Federal do Ceará. Fortaleza, 2017.

PACHECO, M. C. R.; GOLDMAN, F. L. O AHP como modelo matemático: uma análise de sensibilidade simples. In: XIII Simpósio de Excelência em Gestão e Tecnologia, 2014. Anais...

ROY, B. Multicriteria methodology for decision aiding. Netherland: Kluwer academic publishers, 1996.
SAATY, T.L. A scaling method for priorities in a hierarchical structure. Journal of Mathematical Psychology, v. 15, p. 234-281. 1977. https://doi.org/10.1016/0022-2496(77)90033-5

SAATY, T. L. Decision making with the analytic hierarchy process. International Journal of Services Sciences, Pittsburgh, v. 1, n. 1, p.83-98, 01 jan. 2008.

SAATY, T. L. On the Measurement of Intangibles: A Principal Eigenvector Approach to Relative Measurement Derived from Paired Comparisons. Notices: of the American Mathematical Society, Providence, v. 60, n. 2, p.192- 208, 01 fev. 2013. http://dx.doi. org/10.1090/noti944

SEMACE. Portaria $\mathbf{n}^{\circ} \mathbf{1 5 4}$, de 22 de julho de 2002. Dispõe sobre padrões e condições para lançamento de efluentes líquidos gerados por fontes poluidoras. Diário Oficial do Estado. 01 de outubro de 2002.

VARGAS, R. Utilizando a Programação Multicritério (AHP) para Selecionar e Priorizar Projetos na Gestão de Portfólio. PMI Global Congress - North America. Washington, 2010. 